\title{
LAS CORRIDAS DE TOROS EN LOS PUEBLOS MAYAS ORIENTALES UNA APROXIMACIÓN ETNOGRÁFICA
}

\author{
Andrés Medina Hernández \\ Instituto de Investigaciones Antropológicas, UNAM \\ Francisco Javier Rivas Cetina \\ Centro de Investigaciones y Estudios Superiores en Antropología Social, \\ Sede Peninsular
}

\begin{abstract}
Resumen: En este ensayo realizamos una descripción de las corridas de toros en los pueblos mayas del oriente de Yucatán; la intención principal es situar esta expresión festiva en el contexto de los rituales que configuran las fiestas patronales, de tal manera que se destaque un hecho central: la profunda transformación de una fiesta de claros orígenes ibéricos en una manifestación profundamente entramada con una visión del mundo de raiz mesoamericana. Un eje de análisis es el que corresponde a las nociones de sacrificio que articulan los acontecimientos en el coso taurino con los más discretos que suceden en el interior de las casas de los dirigentes de los gremios, donde el sacrificio de puercos y pavos constituye la base de una gastronomía ritual. Otro más es el reconocimiento de referentes simbólicos espaciales y temporales de raíz mesoamericana que subyacen en todo el conjunto ritual que compone estas celebraciones de los mayas peninsulares.
\end{abstract}

Palabras Clave: tauromaquia, mayas peninsulares, etnografia maya, fiestas patronales, ritualidad comunitaria.

Azstract: In this essay we describe bullfighting among the Maya peoples in eastern Yucatan. The fundamental aim is to situate this festive expression in the context of the rituals that shape the patron feasts, so as to stress a central fact: the transformation of a feast of clear lberian origin into a manifestation that is deeply intertwined with a world vision of Mesoamerican ancestry. An analytical axis corresponds to the notions of sacrifice that articulate the events inside the bullring with those more discrete, that take place within the homes of the leaders of the guilds. Here, sacrifice of turkeys and pigs constitute the basis of a ritual gastronomy. Another axis is the acknowledgement of symbolic space and time referents of Mesoamerican origin underlying, as a whole, the ritual compound in these peninsular Mayan celebrations.

Kfrwords: bullfighting, Peninsular Maya, Mayan ethnography, Patron feasts, community rituality.

RECEPGón: 4 de febrero de 2009.

Acriptación: 27 de marzo de 2009 



\title{
LAS CORRIDAS DE TOROS EN LOS PUEBLOS MAYAS ORIENTALES. UNA APROXIMACIÓN ETNOGRÁFICA
}

\author{
Andrés Medina Hernández \\ Instituto de Investigaciones Antropológicas, UNAM \\ Francisco Javier Rivas Cetina \\ Centro de Investigaciones y Estudios Superiores en Antropología Social, \\ Sede Peninsular
}

\section{Introducción}

Las corridas de toros son una parte fundamental de las fiestas patronales en las comunidades mayas de la península de Yucatán; articuladas al conjunto ritual que se despliega en las celebraciones festivas, aparecen, en una primera mirada, como una versión no muy distante de la tradición que llega con los conquistadores y colonizadores hispanos en el siglo xv. Sin embargo, una aproximación más atenta descubre pronto diversos detalles que son llamativos, tales como el árbol instalado en el medio del ruedo, o el hecho de que solamente el primer toro es matado por uno de los toreros; o bien que los trajes de los toreros no tienen la fastuosidad y finura de los trajes de luces, ni que la faena desarrollada se adorne con los pases y figuras que destaquen la "graciosa entrega" de la fiesta taurina de las grandes ciudades mexicanas y españolas; de hecho no son ellos los protagonistas, sino los vaqueros y los toros mismos.

En este ensayo nos proponemos hacer una descripción etnográfica de las corridas de toros de las comunidades mayas del oriente de la península, lo que implica no sólo referirnos a las características específicas de la tauromaquia, sino también al marco ceremonial que le rodea y le otorga su sentido. Al final propondremos una primera interpretación, pero sobre todo nos interesa apuntar diversas líneas de reflexión para profundizar en una manifestación cultural que, procedente de la tradición ibérica, se ha transformado en una manifestación vinculada profundamente con las tradiciones religiosas mesoamericanas.

\section{Los antecedentes ibéricos y su recepción mexicana}

La fiesta brava contemporánea es el resultado de un largo proceso histórico en el que se perfilan diferentes tradiciones; sin embargo, una de ellas, la de Andalucía, 
se habría de convertir en la fiesta nacional hispana y se impondría como la hegemónica en España y en las colonias que componían su imperio. La particularidad de esta tradición imperial es la muerte pública del toro y la celebración de la faena individual por el matador a cargo; en cambio, en las otras tradiciones no se mata al toro en el ruedo y lo que se realiza es una serie de juegos en la que los diversos participantes compiten. Como lo ha estudiado con una perspectiva teórica original Frédéric Saumade, al lado de la tradición nacional andaluza encontramos la portuguesa, la navarro-aragonesa, la valenciana, la camarguesa y la landesa (Saumade, 2006). Todas ellas arraigadas en antiguas tradiciones religiosas ibéricas, pero sobre todo relacionadas con la ganadería y con los juegos a caballo.

La invasión hispana en América trajo consigo la ganadería, y con ella la tradición taurina; la primera hacienda ganadera la estableció Hernán Cortés en San Mateo Atenco, Estado de México. Por otra parte, la primera corrida de toros fue la realizada en 1526 para celebrar el retorno de Hernán Cortés de las Hibueras, y a partir de 1529 el Ayuntamiento de México las organiza por su cuenta, en la fiesta de San Hipólito, el 13 de agosto, fecha de la caída de México-Tenochtitlan. Las corridas consistían en el alanceo de los toros, es decir, un deporte ecuestre, inseparable del "juego de cañas"; los toros que lidiaban en una fiesta llegaron a ser 40 . "El caballero hostigaba y trataba de matar al burel con una lanza de combate a la manera del rejoneador moderno; y si no lograba sacrificar el animal, entraba en funciones, a pie, un mozo de espuela con capa y espada. Éste daba fin a la bestia y con el tiempo se convirtió en el 'matador', figura principal de la plaza de toros desde fines del siglo xvi"' (Weckmann, 1996: 131).

A partir de 1586 se armaba un coso en la Plaza del Volador, a un costado del palacio virreinal, para celebrar con corridas de toros las fiestas reales y la entrada de los virreyes; estas corridas, apunta J. P. Viqueira, eran la ocasión para mostrar el orden jerárquico novohispano, pues además de que el virrey tenía un palco especial, todas las autoridades ocupaban sus respectivos suntuosos palcos (Viqueira, 1991: 34).

Con el establecimiento de las haciendas en el territorio novohispano y su expansión en el siglo xIx, las artes relacionadas con la ganadería y con el dominio ecuestre adquieren una notable presencia hasta el grado de convertirse en un símbolo de la identidad nacional, en un largo periodo que llega hasta fines del siglo veinte. Sin embargo, el montar a caballo era un privilegio reservado a los españoles y a la nobleza criolla durante el periodo novohispano, pues no les estaba permitido a los indios. No obstante, las actividades desarrolladas en las haciendas ganaderas, en las que participaban caporales mulatos y mestizos, involucraban también a peones indios que aprendían las habilidades requeridas para el manejo del ganado. Las ferias regionales y las festividades de los centros urbanos proporcionaban la ocasión para el concurso de los más diestros en las habilidades para montar a caballo y para los juegos entre jinetes, como los de cañas, y con los toros. 
Con el advenimiento del movimiento revolucionario de principios del siglo $\mathrm{xx}$ y con la reforma agraria que auspició, se generó un intenso proceso de reconstitución de las comunidades indias, muchas de ellas devoradas materialmente por las haciendas, y con ello el inicio de una efervescencia para reinventar sus tradiciones, entre las cuales muchas de ellas eran una apropiación de aquellas que les eran vedadas, con lo que se habría de desplegar una original reelaboración hasta transformarlas en una parte de sus propias tradiciones culturales, profundamente entramadas con aquellos referentes centrales de su identidad. Tal es el caso, por ejemplo, de los pueblos campesinos de Morelos, en el Altiplano Central.

Los viejos de la región morelense todavía recuerdan los juegos con los toros que se hacían en las haciendas, así como el largo camino para apropiarse de tales festejos e integrarlos a sus celebraciones festivas. Actualmente la fiesta de "los toros" forma parte de las fiestas patronales de pueblos y barrios, o bien de otras dedicadas a santos de las devociones locales. "Algunas veces los días dedicados a 'los toros' son más que los días destinados a los festejos propiamente religiosos, que difícilmente son más de tres días" (Morayta, 1992: 13).

Resulta muy sugerente conocer la variante taurina morelense, pues nos indica las formas diversas que puede asumir esta vieja tradición ibérica; en tales celebraciones la figura central son los montadores, estando los toreros en un lugar secundario.

La obligación de los toreros en un festejo de toros es la de proteger a los montadores más que lucirse en sus lances. Con gabanes y sarapes a manera de capotes los toreros tratan de que los toros los embistan a ellos en lugar de que embistan a los montadores que han sido derribados. Los pases que normalmente se realizan en la lidia formal de toros - verónicas, chicuelinas, afarolados, etc.- muy raramente se ven en la monta de toros, aquí la idea es otra. Antes de que inicie el festejo, los montadores o sus parientes y amigos buscan un torero que los proteja durante la monta. Algunos ya tienen torero dentro de su propia palomilla. Los que no, piden el favor a algún torero conocido (Morayta, 1992: 44).

Una tradición que forma parte de las corridas de toros, y que ha desaparecido en muchos lugares, es la que asume una versión lúdica, la que en Morelos se realizaba con mojigangas y xiñolas. Las mojigangas, grandes figuras hechas de cartón, representaban, con rasgos ridículos, a personalidades locales o de la política regional y nacional, las cuales se situaban al centro del ruedo para que fueran destrozadas a cornadas; o bien se les montaba en los toros para ser derribadas. "Por su parte, algunos montadores se disfrazaban de mujeres y así ejecutaban su monta, éstos eran las xiñolas, como los personajes de ciertas danzas tradicionales. Otros montadores lo hacían en parejas, uno mirando hacia delante y el otro hacia atrás, agarrado casi de las verijas. Todas estas suertes le daban un toque carnavalesco al festejo" (op. cit.: 53).

Desafortunadamente la etnografía mexicana ha descuidado la investigación sobre las tradiciones de tauromaquia y de juegos a caballo que llegan con la in- 
vasión y colonización hispanas; relacionadas con la "cultura de conquista", como la llamó George M. Foster, no hemos estudiado las maneras en que esta tradición ha sido apropiada en las diferentes regiones del país, no obstante ser un referente para la configuración de la identidad nacional desde el siglo xIx; pero lo más sorprendente es el desconocimiento de las formas diversas en las que los pueblos indios han reaccionado a esta tradición. La prohibición de montar a caballo y poseer ganado mayor a las comunidades indígenas no se aplicó a aquellos contingentes indios aliados de los españoles que se dirigen al norte del país, como es el caso ampliamente conocido de los tlaxcaltecas, entre otros (Martínez Saldaña, T. 1997), y al sur, con mexicanos y tlaxcaltecas, como lo atestiguan los barrios de indios en ciudades coloniales como Oaxaca, Mérida y San Cristóbal de las Casas, Chiapas (Bracamonte, 2005).

El proceso de apropiación y utilización diversa de las tradiciones ganaderas y ecuestres se acentúa en el siglo xix, y alcanza una mayor intensidad en el siglo xx, como resultado de los efectos de la reforma agraria y del propio desarrollo de la economía nacional.

Hasta ahora solamente tenemos el trabajo etnográfico pionero de Miguel Morayta, citado antes, así como las investigaciones de Frédéric Saumade, pero nos falta mucho por conocer; un ejemplo de las sorpresas que nos depara escudriñar con atención las tradiciones relacionadas con la tauromaquia y los juegos a caballo es el caso de los pueblos mayas que aquí expondremos sumariamente, y que merece un seguimiento de mayor profundidad.

\section{Las fiestas patronales en los pueblos mayas}

Uno de los acontecimientos más importantes en los ciclos ceremoniales de las comunidades mayas es la celebración de las fiestas patronales, cuando tienen lugar muy diversos acontecimientos que implican la inversión de grandes cantidades de recursos materiales y la movilización ordenada de numerosos contingentes. Estas actividades están a cargo de grupos de personas representativas de la comunidad, que reproducen tradiciones organizativas establecidas sólidamente en el periodo novohispano y en las cuales se conjugan de muy diversas maneras las instituciones hispanas con las concepciones mesoamericanas de los campesinos mayas. Para los pueblos peninsulares se reconocen tres tipos de organización: las cofradías, el sistema de guardias y los gremios (Quintal et al., 2001a).

La cofradía llega con la tradición cristiana medieval de los españoles, pero asume formas diferentes en el medio urbano, donde sigue la forma de organización voluntaria en torno a una figura religiosa, y en el medio rural, donde el culto a los santos adopta formas comunitarias, es decir, incumbe a todos los miembros y se articula al ciclo ceremonial comunitario. "Los aspectos religioso y económico de la cofradía se concretan en sus cargos principales: patrón, mayordomo, prioste, escribano, mayol y vaqueros. Además, con fines de acopio de 
recursos necesarios para el financiamiento de algunas actividades culturales y ceremoniales se nombraban diputados" (Quintal et al., 2001a: 351).

El sistema de guardias es la forma que asume la cofradía entre los mayas rebeldes, quienes se organizan en "compañías", con sus grados militares, a partir de la "guerra de castas" que estalla en 1847 y continúa prácticamente hasta la tercera década del siglo veinte. Estos mayas son los que forman parte del estado de Quintana Roo y han desarrollado una tradición cultural que, en algunos aspectos, toma distancia de la del resto de los mayas peninsulares. En estas comunidades, adelantemos, la tradición de la corrida de toros tiene una fuerte presencia y adquiere formas mucho más ritualizadas, de tal suerte que para entender diversas particularidades presentes en las corridas de toros de las comunidades mayas peninsulares habrá que realizar comparaciones para reconocer variantes regionales, como la de los cruzoob o macehualoob.

En sentido estricto, las diferencias entre los pueblos mayas peninsulares tienen un referente que los marca profundamente en la Guerra de Castas; un conflicto armado que se mantiene vivo por un poco más de ochenta años incide, sin duda, en el desarrollo social y cultural de los pueblos en pugna. Es en este escenario que tiene que situarse el proceso de diferenciación expresado en las organizaciones comunitarias. Mientras que en los mayas rebeldes, los cruzoob, la situación militarizada y distante del control de los centros urbanos de tradición española y criolla les permite desplegar sus recursos culturales y reinventar sus tradiciones de raíz mesoamericana, los pueblos bajo el control de la "casta divina", es decir los grandes hacendados y funcionarios urbanos, son sometidos a una mayor vigilancia y reorganizados; para distinguirlos de los cruzoob, a los que se les continúa llamando "indios", se les asigna el nombre de "mestizos". Lo cierto es que en uno y otro caso se abandona la organización político-religiosa procedente del antiguo cabildo de indios colonial, la cual en los otros pueblos mesoamericanos se transforma en lo que los antropólogos funcionalistas llamarán el "sistema de cargos". En este contexto se desarrollará en las comunidades mayas "mestizas" la organización de origen urbano de los gremios, reelaborada para adecuarse a la cultura comunitaria.

Los gremios tienen su origen medieval en la agrupación urbana establecida de acuerdo con la ocupación de sus miembros, es una especie de mutualidad para protegerse en situaciones críticas de enfermedad y en los funerales. El traslado de los gremios a las comunidades campesinas mayas conlleva varias adecuaciones; una de ellas es la del predominio de los vínculos de parentesco como base de su organización, a la que se añaden las relaciones de amistad y de vecindad. Otra característica es la de repartirse la organización de las fiestas patronales de tal suerte que cada día festivo queda a cargo de un gremio diferente; y una más, es el establecimiento implícito de una jerarquía entre los gremios, siendo el de mayor importancia el que tiene a cargo el día principal de la fiesta, cuando se tienen los gastos mayores y comienza el ciclo de las corridas de toros.

La participación de los gremios en la celebración festiva patronal establece el 
marco general específicamente religioso, tanto con los rituales que se realizan en la casa del presidente de cada gremio - y cada día interviene uno diferente-, como los que tienen lugar en la iglesia (como llevar los estandartes y pendones, así como trasladar la imagen religiosa principal a la casa del presidente). El cierre del ciclo festivo se señala con la procesión que se realiza en las calles de la comunidad con la participación de todos los gremios y el conjunto de creyentes.

En Popolá, comunidad al norte de Valladolid, los gremios se componen de donantes, quienes al ingresar se comprometen a hacer una ofrenda al santo en el día de su fiesta, tal ofrenda es la entrega de comida para el santo y el pago de una misa. Las misas se celebran a lo largo de una novena, pero si los donantes que se apuntan con el prioste rebasan este lapso, las misas se prolongan por más días, hasta 15 o 23. En las misas se hace entrega de velas decoradas, adornos de cera de abeja y de ramilletes (elaboradas armazones de varas que se cubren con una gran cantidad de pliegos de papel de china de diferentes colores, calados y recortados formando figuras artísticas). En cada día el donante responsable prepara el platillo ritual por excelencia, el relleno negro (pavo horneado en el pib, hoyo o zanja abierto en la tierra donde se calienta con leña una cama de piedras, sobre la cuales se acomodan las ollas con el pavo condimentado, y se cubre con ramas y tierra toda la noche, para descubrirse y servirse a la mañana siguiente). Las primeras porciones de comida se ofrecen al santo patrono, así como a los santos del altar casero y a los difuntos de la familia (Quintal et al., 2001a: 362).

Es fundamental apuntar, para vincularlo con el significado que pueda tener la corrida de toros, que en esta secuencia ritual tiene un lugar importante el sacrificio de cerdos y guajolotes (a los que se llama en el español local "pavos"), los cuales son preparados para ser cocinados en el horno subterráneo, el pib, del cual emergen como alimentos rituales marcados por el color negro. Por una parte la carne de cerdo se prepara con frijoles negros, platillo que se conoce como "frijol con puerco"; por la otra, lo que es la comida ritual más importante entre los mayas peninsulares, el "relleno negro", el pavo horneado con una salsa entre cuyos ingredientes está una variedad regional de chiles, conocida como "chile verde", la cual se tuesta y muele hasta obtener una coloración negra.

El sacrificio de pavos y cerdos se realiza con la mayor discreción, sin ningún aparato ceremonial; es decir, no está en el centro de los rituales familiares o comunitarios. En los preparativos del banquete que los miembros del gremio ofrecen, en la casa de su presidente, se reúne un considerable número de personas que se organizan para llevar a cabo todas las operaciones necesarias, que en el caso de los pavos y los cerdos implica la limpieza, el destazamiento, la condimentación y preparación para ser horneados (o también cocinados en el fogón doméstico); todo lo cual sucede en el huerto de la casa, en la que se distribuyen grupos de personas de ambos sexos para realizar diversas actividades, durante las cuales conversan y cuentan historias, hacen juegos de palabras y difunden acontecimientos. En ese escenario se lleva a cabo la matanza de pavos y cerdos; a los primeros se les cuelga, por las patas, de una cuerda, alineados, para que 
la sangre que brota al degollarlos escurra en la tierra. Con respecto a los cerdos tenemos una valiosa referencia de Xocen, comunidad maya del oriente.

Los sacrificios de puercos y su preparación en relleno negro son obligatorios en todas las fiestas de santos. En general, la matanza sucede sin ceremonias, pero la fiesta de corrida del pueblo de Xocen indica que, tal vez, no siempre fue así. En la primera mañana de aquella fiesta sacrifican trece puercos, frente a una imagen de la Santa Virgen, la cual llevan a los trece lugares de sacrificios. Cuelgan una corona de flores en el cuello del cochino, colocan al animal boca arriba, en una piedra plana y con un cuchillo lo punzan en el cuello: al asestar el cuchillo al corazón el animal muere (Jardow-Pedersen, 1999: 50).

Veamos ahora el otro lado de las celebraciones festivas patronales, la corrida de toros, donde también aparecen diversas manifestaciones relacionadas con el sacrificio; la más obvia es la del toro que morirá con la espada del torero para luego ser destazado y vendido, en las cercanías del ruedo, a la gente que ocurre, para con su porción preparar un platillo especial, el chocolomo.

\section{Los preparativos de la corrida: la asamblea de palqueros}

En los días previos a los festejos dedicados a la imagen patronal, en el Ayuntamiento "rematan" la fiesta con la intención de buscar al mejor postor. Cuando al fin se logra el acuerdo, el "interesado", es decir el empresario que realizará la fiesta, convoca a una asamblea con el grupo de palqueros o ejidatarios que participan en la construcción del coso taurino, o ruedo; son ellos quienes se encargan de comprar o alquilar las tablas, o bien de cortar los "palos" o "maderos" que servirán para la construcción de los palcos. El interesado, por su parte, ocasionalmente se encarga de llevar tablas y postes hasta el lugar donde se realizarán las corridas, porque esta tarea realmente es obligación de los palqueros, para lo cual emplea diversos vehículos motorizados. Durante la reunión, el empresario de la fiesta expone los pormenores del programa, es decir define los conjuntos musicales que tocarán en los bailes populares y en la vaquería, así como quiénes serán los toreros, el juez de plaza y el número de toros que se lidiarán. Pero la parte que más interesa al grupo de palqueros es lo que se refiere al costo de la parte que se les concesionará para la construcción de los tablados o palcos.

En el caso de Dzitas, por ejemplo, comunidad maya oriental, el empresario de la fiesta convoca a los ejidatarios y les ofrece una cantidad de dinero para la confección del ruedo, además de que les permitirá entrar, con dos o tres miembros de la familia, a gustar la corrida a cambio de que coloque y quite las sillas, antes y después de las corridas, en el espacio en el que construyó el palco. El empresario rodea con malla ciclónica al coso, dejando solamente una entrada para los espectadores; ahí se instala una mesa para el cobro de las entradas. En otros casos, observados en la misma comunidad, se llega al acuerdo de que, al 
concluir la corrida, se contabilicen las entradas y, de acuerdo al boletaje recaudado, se les de un porcentaje del total de las ventas.

En el caso del municipio de Conkal, situado en la parte central de Yucatán, bajo la influencia metropolizante de Mérida, existe un sindicato de palqueros, de tal manera que las primeras negociaciones con el empresario se realizan a través de un representante. Primero, el interesado le informa de los costos y de los detalles del programa, posteriormente el representante de los palqueros convoca a una asamblea para informar a los socios de lo que se está programando y de lo que el interesado pide por cada día de corridas. Cuando se llega a un acuerdo sobre el costo que pagarán por el derecho del palco, se cierran las negociaciones, en las que se discute también la procedencia de los toros que se lidiarán y los toreros que realizarán la lidia. Una vez establecidos los acuerdos y los compromisos, cada una de las partes fija las actividades que se realizarán. Por su parte, los palqueros indican el día en que se iniciará la construcción del ruedo, con la medición y distribución de los espacios; aunque cada quien ya conoce el lugar que le corresponde. Por otra parte, el empresario de la fiesta indica la fecha en la que se entregarán las sillas, definiéndose las que le corresponden a cada palquero.

\section{La construcción del ruedo}

En la construcción del coso taurino se invierte entre una semana a quince días, lo que se realiza en los días previos a la fecha que se señala en el santoral católico que corresponda al santo patrono de la comunidad; aunque es frecuente que en algunas comunidades se organicen dos o tres fiestas al año, con sus respectivas corridas. Por otra parte, es importante señalar que no en todas las comunidades se efectúan y respetan las corridas en el día del santo patrono. Sin embargo, éstas siempre se encuentran inmersas en el contexto de la fiesta patronal y en el tiempo sagrado que incluye novenarios, salida y entrada de gremios, así como la procesión comunal. El ruedo ocupa, casi siempre, un lugar cercano a la iglesia, pues a través de diversos rituales se establece la relación del santo patrón con las corridas de toros.

En la estructura de los palcos o tablados, que se construyen para las corridas de toros, pueden encontrarse de dos y de tres pisos, que incluyen una planta baja, un primer y un segundo nivel. Los de tres pisos se observan principalmente en las zonas sur y oriente del estado; y las de dos pisos se encuentran comúnmente en la zona centro y la costera. La construcción se realiza de la siguiente manera: cuando se traza el ruedo, se marcan dos circunferencias paralelas, separadas por una distancia de tres metros, aproximadamente; en la franja circular establecida se marcan secciones de dos metros con ochenta centímetros. Por supuesto que estas proporciones varían según el tamaño del coso, el número de palcos y la magnitud misma de la comunidad que realiza la celebración. 
Cada uno de los palqueros sabe cuál es el espacio que le corresponde, de tal manera que sólo remueve los hoyos hechos año tras año para la construcción del ruedo. En cada una de las secciones de los palcos que se trazaron, los hoyos que se cavan alcanzan una profundidad aproximada de entre cincuenta y ochenta centímetros para plantar los horcones o parales que servirán de soporte principal de la estructura. Estos horcones se ubican sobre los círculos trazados y en la parte intermedia; posteriormente en dichos horcones se amarran tiras de madera, o gruesas ramas, en forma horizontal por la parte interna, de tal manera que se cierre el círculo y forme una especie de corral. A estas tiras o ramas se les llama katanché; en ellas se amarran palos más delgados, pero con la fuerza y resistencia suficientes para soportar las posibles embestidas de los toros. Las tiras se entretejen diagonalmente, en forma paralela y opuesta, formando pequeños rombos, conocidos como celosías. En la parte que conforma el segundo círculo, el exterior, se amarran palos de diferentes tamaños y distribuidos de tal manera que permitan el tejido de hojas de la palma conocida como "guano", o en su defecto se usan lonas o láminas. Esta forma de construcción se prolonga hasta el segundo y tercer piso.

Entre el segundo y el tercer nivel se ponen tablas como base del piso; o bien, en algunas comunidades se emplean los "palos" o "maderos", es decir, varas, para instalar las sillas — con un ancho de treinta centímetros por dos metros con ochenta centímetros o tres metros de largo, aproximadamente-, dispuestas en una sola dirección y montando una de las puntas de palco a palco. El techo se construye de la misma manera que la parte trasera de la estructura. En algunos casos, como en Kinchil, por ejemplo, los palcos se construyen en dos niveles y en forma de gradas, que permiten una mejor visibilidad para observar la corrida. En el tipo de construcción descrita anteriormente los asientos se distribuyen en un solo nivel, marcándose la primera, la segunda, la tercera fila y las barandas. Tales barandas se sitúan en la parte frontal del segundo y tercer nivel, dentro del ruedo, mediante una tabla que prácticamente está suspendida sobre rieles o tablas muy resistentes; los espectadores que se instalan en tales barandas dejan colgando al aire los pies, hacia el interior del coso.

En el círculo que forman los palcos se deja uno o dos espacios para la entrada y salida de los vaqueros, así como el embarcadero para el descenso y retorno de los toros. En la parte que ocupan las rejas de entrada y salida suele construirse el tercer nivel, que ocupan las autoridades municipales, la diputación, las embajadoras y los invitados especiales, cuando los hay, así como el grupo musical, llamado "charanga", que ameniza la corrida. En todos los casos se puede encontrar un palco de honor para las distintas personalidades que presiden la corrida; este palco es construido bajo la responsabilidad del Ayuntamiento o del empresario de la fiesta. Al concluir el ruedo que servirá para las corridas, la noche de alborada o vaquería se cava un hoyo que sea lo suficientemente profundo para sembrar el tronco o árbol de una ceiba, de guano o de chacté, con lo que se da inicio, de manera oficial, a la fiesta del santo patrono. 


\section{Noche de alborada o vaquería}

La "noche de alborada" es prácticamente una vaquería; sin embargo, hay comunidades que efectúan una jarana a mediodía, después de la noche de alborada o de vaquería, y antes del inicio de la primera corrida de toros. Durante estos bailes se organizan concursos para seleccionar a los mejores bailadores de la región.

En la casa del diputado del gremio o del presidente del club jaranero de la comunidad, comienzan a reunirse, entre las nueve y diez de la noche, los jaraneros, hombres y mujeres de diferentes edades vestidos con el traje regional de gala, el terno finamente bordado que consta de fustán, huipil y solapa. En ocasiones se puede observar algún aditamento en el terno, como cintas delgadas y de diferentes colores que se prenden a la ropa como un pasador, o cintas igualmente largas en los sombreros que usan como galas. Esto se emplea como un distintivo para identificar a una sociedad jaranera o grupo de danza. El ajuar se complementa con un tocado de flores prendido en el pelo y ligeramente detrás de la oreja; en algunos casos con las galas. Estas galas son sombreros decorados con una cinta de color, un ramo de flores y en ocasiones un pequeño espejo circular puesto en la parte frontal. Ésta es la forma estilizada, pues la verdadera gala es puesta por un jaranero a la bailadora como un reconocimiento a su destacada manera de bailar, en el acto mismo del baile, y pueden ser varias las galas otorgadas, puestas una sobre la otra. Al término de la jarana, el dueño del sombrero lo recoge y le hace un obsequio a la bailadora, que consiste en una cantidad de dinero.

Las orejas se adornan con aretes largos y vistosos, pueden ser de filigrana, de la rica tradición artesanal yucateca, o de cualquier otro diseño que armonice con el terno. El cuello es engalanado con rosarios, gargantillas de dos vueltas con sus medallas y campos, así como con todo tipo de parafernalia en joyería, que puede ser de fantasía fina, en oro con coral rojo o filigrana, según el gusto y la posibilidad económica de las bailadoras. Las muñecas pueden adornarse con semanarios y con pulseras de diferente confección; en los pies portan zapatos blancos, propios para el baile, de tacón ancho y altura media; en algunos casos el zapato, forrado de raso, puede estar bordado con un diseño similar al del terno. Para enmarcar su elegancia las bailadoras portan un rebozo y llevan discretamente un pañuelo blanco en la mano para secar el sudor de su rostro, cuidando de no retirar el maquillaje y, en ocasiones, un abanico de mano para mitigar el calor.

En el caso de los hombres el ajuar es más sencillo; consta de un pantalón blanco y filipina, sombrero de jipi o sintético y pañuelo rojo (en algunos casos se han observado pañuelos blancos con bordados diversos, semejantes a los que se ven en los ternos). El atuendo masculino se completa con un par de alpargatas chillonas, confeccionadas especialmente para bailar las jaranas.

Entre las nueve y diez de la noche, el grupo reunido de bailadores se dirige al centro de la población, formando una sola fila en parejas; la mujer cruza su brazo izquierdo en el brazo derecho del hombre. Suele suceder que sean más las 
mujeres que los hombres, por lo que es muy común que algunos de los hombres entren al área de baile con dos mujeres, una en cada brazo. De igual manera, es posible observar a mujeres bailando entre sí, a falta de hombres que las inviten a bailar, o porque no hay hombres a los que les interese bailar la jarana.

El recorrido, que se inicia en la casa del diputado y prosigue hasta el centro de la población (sitio donde se realizan las jaranas), va acompañado del estallido de los cohetes, o "voladores", como se les llama localmente, y de la música interpretada por algunos de los músicos de la orquesta jaranera, quienes van a buscar a la comitiva. Durante el trayecto se interpreta la jarana conocida como "angaripola" o pasacalles. Al llegar al centro de la población el grupo de jaraneros se dispone a entrar al lugar del baile, en tanto que la orquesta se alista con los músicos que acompañaron a los jaraneros. Finalmente, la entrada del grupo es anunciada y se recibe al grupo con "dianas", mientras recorren el lugar del baile. Hecho esto, se anuncia la entrada de los diferentes grupos invitados, sea de los poblados vecinos, o incluso del interior del estado. Al anunciar la entrada de cada grupo jaranero, se mencionan los nombres de su embajadora y de su representante, quienes son acompañados, a su vez, por la embajadora y el representante del club jaranero anfitrión, quienes les dan la bienvenida y los invitan a pasar. En algunas ocasiones, mientras el grupo visitante se organiza para entrar, la orquesta interpreta una jarana a fin de darles tiempo para preparar su ingreso al espacio del baile.

Al término de la recepción de los grupos jaraneros se corona a la "reina de la feria" y a las embajadoras. Posteriormente, la embajadora y el alcalde pronuncian un discurso para invitar a todos a participar en la fiesta. Finalmente, da inicio la fiesta patronal, de manera oficial, con la jarana "Aires del Mayab". Estalla entonces la algarabía y se queman juegos pirotécnicos, principalmente "hiladas" y "voladores". Mientras tanto los jaraneros toman su lugar en la pista de baile y comienza la fiesta.

En el transcurso de la noche, y ya en la madrugada, se hace una invitación a los jaraneros, $\mathrm{y}$ a las personas que así lo deseen, para acompañar a la diputación que va en busca del yaxché, para llevarlo y plantarlo en el ruedo donde se realizarán las corridas de toros. Este árbol sagrado, ceiba en español, es llevado con música y "voladores", mientras se va repartiendo cigarros, aguardiente o cerveza entre los señores que lo cargan en hombros y a las personas que los acompañan. Al llegar al ruedo, la ceiba -o bien guano o chacté- es sembrada en un hoyo excavado de antemano, mientras el conjunto musical interpreta una jarana.

Al término de la siembra del yaxché se interpreta una "diana" y todos regresan al centro de la plaza, para continuar con el baile, el cual normalmente termina entre las tres y cuatro de la madrugada con la jarana conocida como "El torito". Esta jarana, que marca el final del baile, tiene la particularidad de que en su realización la mujer personifica al toro, en tanto que el hombre asume la posición del torero. Así, se da por concluida la noche de alborada y se abre paso a las corridas de toros, que comenzarán por la tarde. En algunos lugares suele 
efectuarse una vaquería, o baile de vaqueras, en el transcurso del día que sigue a la noche de alborada.

La importancia de las vaquerías en los pueblos mayas reside en expresar el inicio de los festejos dedicados al santo patrono de cada comunidad; y resulta difícil encontrar una fiesta patronal sin la corrida de toros, ya que desde el inicio de la construcción del coso taurino los pobladores, y gente que transita por la comunidad, expresan: iEstá de fiesta el pueblo! Vale la pena señalar aquí que, en la mayoría de las poblaciones, las festividades dedicadas al santo patrono se llevan a cabo durante el fin de semana más próximo al que marca el santoral católico para su veneración, lo que puede realizarse días antes o después.

\section{Las corridas de toros: el escenario}

Entre las tres y cuatro de la tarde, después de la noche de vaquería, se ultiman los detalles para la seguridad de los toreros y se instalan las "guardaderas" o burladeros; cerca del coso taurino se revientan los primeros "voladores" para anunciar a la población que la corrida está por comenzar. Por diferentes rumbos de la población se puede ver a las familias dirigirse al lugar donde se realizará la corrida. En los palcos, los encargados comienzan a disponer las sillas que les corresponden para acomodar a los espectadores. Los toreros contratados para esa ocasión comienzan a vestirse en la casa o cuarto que se les asigna. Los vaqueros de la comunidad ensillan los caballos para entrar a lazar y la diputación comienza a reunirse en el palacio municipal. Este tipo de actividades se observan principalmente en las comunidades del oriente y el sur de Yucatán.

Cuando se revientan los siguientes "voladores", se observa ya movimiento de gente en los palcos, y alrededor del coso, tratando de conseguir el mejor lugar para disfrutar del espectáculo. Los vendedores ambulantes ofrecen diferentes tipos de golosinas y antojitos, tales como: chicharrones de harina, palomitas de maíz, "marquesitas", algodones de dulce, "bolis", paletas de hielo, cacahuates y pepitas de calabaza tostadas con sal y chile, mangos y jícamas condimentados con sal, chile y limón, entre otros. En los puestos semifijos que rodean el coso se expenden refrescos embotellados y comida; los juegos mecánicos para los niños comienzan a funcionar, en tanto que niños y adultos se acercan a curiosear y consumir, en la medida de sus posibilidades. Todo el escenario está puesto ya para dar inicio a la corrida. Las camionetas con los toros esperan su turno cerca de la reja de entrada al ruedo, mientras que la charanga comienza a interpretar diversas jaranas, hasta que las autoridades se presenten con la diputación para dar inicio a la corrida.

\section{La primera corrida}

La corrida comienza cerca de las cuatro o cinco de la tarde, y en ocasiones hasta las seis. La diputación es encabezada por alguna autoridad local, y ocasionalmen- 
te por el presidente municipal, la embajadora de la feria y demás personalidades que representan la autoridad en el municipio y poblados circunvecinos, así como de los ganaderos. Por delante van los coheteros reventando los voladores, inmediatamente les sigue la diputación con su comitiva y, al final, cierra el contingente la charanga, que interpreta dianas durante el recorrido, el cual se realiza en el sentido opuesto a las manecillas del reloj. A este recorrido que realiza la diputación se le denomina "coronar el ruedo". Al salir la diputación del ruedo, la charanga y la comitiva ocupan su lugar correspondiente en el palco de honor para dar inicio a la corrida.

En las camionetas donde se encuentran enjaulados los toros, varios muchachos y señores comienzan las maniobras para cinchar al ganado y prepararlo para la lidia; prácticamente funcionan como toriles. Cinchar al toro implica una destreza particular para no ser embestido por el animal, ya que se le cruza una cuerda a manera de cinturón, que se ubica ligeramente detrás del pecho; amarrado y ajustado por arriba del morrillo, se prolonga pasando parte de la cuerda por debajo del rabo del animal, apretando lo más posible, con la intención de mermarle energía.

Los toreros se ponen de acuerdo y se disponen a partir plaza. La charanga anuncia su entrada con un pasodoble y el juez de plaza, montado en su caballo, encabeza el recorrido, ligeramente detrás le siguen los toreros. Las rejas se cierran y los vendedores ambulantes buscan resguardarse antes de que el toro sea liberado. En el ruedo se encuentra siempre el juez de plaza y los toreros, mientras que desde las barandas algunos muchachos buscan llamar la atención del toro. Cuando la reja se cierra, los vaqueros que se encuentran en el callejón comienzan a "pelear reja", es decir dan empujones con los caballos para tratar de ser los primeros en entrar a lazar; es una lucha sorda y violenta en que cuenta mucho la fuerza y la habilidad para el manejo del caballo. Generalmente el primer toro que se lidia es sacrificado en el ruedo.

Cuando todo está dispuesto, el juez de plaza da las indicaciones, en el momento que considera oportuno, para hacer el cambio de tercios, cuando los hay. Antes de que sea liberado el primer toro se ponen en el suelo del ruedo dos o tres juegos de "hiladas", los que se prenden cuando el animal aparece por el embarcadero, causando una densa humareda por el estallido de los petardos que la componen. La charanga interpreta el toque de entrada para liberar al toro; los toreros se distribuyen por las diferentes "guardaderas" para hacer correr al toro por todo el ruedo; sin embargo, con frecuencia esto no sucede debido a que los toros no tienen el bravío para este tipo de suertes. El primer toro, que suele ser de la raza cebú, casi siempre es sacrificado. En algunas comunidades se puede observar que el toro es conducido por algunos vaqueros, que lo llevan lazado por el cuello hasta el árbol o tronco sembrado en el centro del ruedo. Después de liberar al primer toro y de intentar algunos pases con el capote, se ordena el cambio de suerte para las banderillas, y casi inmediatamente después se ordena el toque de espada, para ejecutar la muerte del toro. 


\section{Los toreros}

Los toreros que se contratan para la fiesta patronal, generalmente cuatro o seis, son de diferentes edades; el traje que portan casi siempre es confeccionado por ellos mismos o por familiares suyos y dista mucho de ser un verdadero traje de luces. Cuando parten plaza los toreros para iniciar la corrida, se forman en cuadrilla, con el torero principal al centro y adelante; se persignan, escupen al suelo y marcan la tierra, en forma de cruz con el pie derecho, en el lugar donde cayó la saliva; se miran entre sí y saludan con la mano extendida, o con la montera, a los espectadores - si es que los tienen-y por último elevan su mano al cielo como tratando de brindar la faena. En otros casos recogen un puñado de tierra y con ella se persignan y la avientan, esparciéndola al mismo tiempo que saludan a los espectadores, con el mismo gesto de brindis.

Los toreros hacen el paseo con la capa sobre el hombro derecho o con una mantilla que lleva bordada la imagen del santo de su devoción, que muy frecuentemente es la virgen de Guadalupe, en tanto que los mozos llevan banderillas, espadas y muletas hacia el burladero, que se sitúa enfrente de la salida de los toros, esperando ser ocupadas en la faena del toreo. Las faenas son diferentes a la lidia de la tradición nacional andaluza; los toreros despliegan más bien una especie de juego, apenas si alcanzan a mantenerse en un solo sitio para aguantar la embestida del toro; lo citan de lejos y, apenas se desplaza para embestir, corren tratando de alcanzar los burladeros, incluso lanzan a un lado el capote para alejar al toro que los amenaza. Después de esta especie de juego y toreo el fin se anuncia con música, para dar paso entonces a los inquietos jinetes que se revuelven en la reja, quienes se lanzan en estampida para lazar al toro y sacarlo del ruedo. Al final de la corrida los toreros se retiran discretamente, saliendo por el callejón sin llamar la atención de los espectadores.

\section{Los toros}

Actualmente los toros que se llevan a las corridas son de ganaderías locales o de las regiones que cuentan con un hato ganadero para rentar; los toros que ofrecen son animales de varias campañas; es decir que han sido toreados en diferentes lugares y en constantes ocasiones, de tal suerte que la gente que gusta de las corridas reconoce a los animales fácilmente e identifican la ganadería de donde proviene. Esto convierte a la corrida en un riesgo constante para los toreros, pero sobre todo para los vaqueros, debido a que el toro no se va ya con el engaño de los pases y, en ocasiones, cuando la charanga anuncia la salida del toro, el animal se para enfrente de la reja para esperar a los vaqueros que entran para sacarlo, con lo que frecuentemente embiste a los caballos, destripando a algunos e incluso matándolos. Estos toros llegan a ser ampliamente conocidos por su nombre y cuando se anuncia la ganadería, o incluso la presentación del 
toro bravo, la gente acude a verlo esperando repita sus hazañas, como sucedió en el caso del toro llamado "El sinaloense".

Los toros que se meten al ruedo por lo general son devueltos a la camioneta que los condujo, con la excepción del primero, que suele ser uno o dos de la raza cebú, al que se mata para vender su carne. Cuando el toro es sacrificado en el ruedo, el abastecedor, o carnicero, corta la yugular del animal, mientras los vaqueros tiran sus sogas para lazarle las patas traseras y realizar el arrastre hasta el lugar donde será destazado, fuera del ruedo, la carne se vende para preparar un caldo que se conoce como chocolomo (caldo caliente de lomo).

\section{El juez de plaza}

El juez de plaza es el encargado de vigilar todo el desarrollo de las corridas, de principio a fin, cada uno de los días que dure la fiesta patronal. El empresario que realiza la fiesta contrata a uno de los vaqueros más destacados y hábiles con el lazo, de carácter fuerte y con capacidad para tomar decisiones en el momento que se requiera durante el desarrollo de las corridas, a fin de brindar seguridad a los toreros. En algunas comunidades es común encontrar al juez de plaza dentro del ruedo con todo y caballo durante la lidia. Desde su corcel da órdenes para liberar al toro, cambiar al tercio de banderillas o espadas, o bien sacarlo y devolverlo a la camioneta, en caso de que no sea el dedicado a ser matado. Por otra parte, también es el que se encarga de vigilar que ninguna persona que no sea torero intervenga en la lidia, a menos de que solicite permiso para torear y que le sea concedido. Antes de que sea liberado el toro, el juez de plaza pide que se retiren todos los que se encuentran en el ruedo para poder cerrar la reja; asimismo indica a los venteros de golosinas y antojitos que busquen un lugar seguro o bien salgan mientras el toro se encuentra en el ruedo. Estos venteros ofrecen sus productos durante toda la corrida, dando vueltas una y otra vez por todo el ruedo, o bien entre el público que se encuentra en los palcos. De igual manera el juez retira a los vaqueros que se encuentran dando vueltas con sus corceles por el ruedo. Por otra parte, en el caso de que ocurra un accidente durante la lidia o que el toro no permita abrir la reja para que entren los vaqueros a lazarlo, el juez de plaza tiene la obligación de lazar al toro para evitar que se escape cuando la reja sea abierta.

\section{Los vaqueros}

Éstos ocupan un lugar importante durante la corrida, ya que en ellos recae la responsabilidad de atrapar al toro con el lazo y evitar que se escape. Desde muy temprano, antes del mediodía o en el transcurso de las primeras horas de la tarde, los vaqueros de la comunidad bañan a sus caballos y los cepillan, para 
después ensillarlos y dirigirse a la corrida. Es común ver a vaqueros que se trasladan con remolques, llevando caballos de fiesta en fiesta y de corrida en corrida. Antes del inicio de la corrida, los vaqueros se pasean en las cercanías del ruedo, dando vueltas y mostrando discretamente sus habilidades para montar y, ocasionalmente, para tirar el lazo. Esta conducta exhibicionista es observada principalmente por las muchachas, algunas de las cuales se atreven a pedir a alguno de los vaqueros les den una vuelta a caballo. Sin embargo, la demostración más espectacular y efectiva se realiza cuando el toro es lazado en el ruedo y sacado para devolverlo a la camioneta que lo llevó; esta experiencia se efectúa luego de la faena con cada toro, cuando el juez de plaza indica el momento de ingreso de los vaqueros, lo que hacen impetuosamente, ondeando los lazos con los que tratan de atrapar al burel.

Desde el momento en el que se cierra el acceso al ruedo, los vaqueros comienzan a "pelear reja" con la intención de ocupar el mejor lugar para el momento en que se abre la puerta y tener así mayores posibilidades de atrapar al toro. Ese momento es de tensión entre los vaqueros, y los espectadores, siempre atentos a lo que ocurre dentro y en las cercanías del ruedo. En el apretado espacio del callejón, los vaqueros pelean su espacio, azuzando con la reata a sus caballos, los cuales muerden, patean y relinchan hasta, ocasionalmente, quedar en dos patas y sobre otro caballo. El número de jinetes y sus briosos corceles que participan en el lazado de los toros va de diez hasta treinta o cuarenta, con lo que puede provocarse un verdadero caos al momento de tirar el lazo. Esto ocasiona accidentes entre los vaqueros, los que pueden caer del caballo, o con todo y él, o bien cruzarse en el trayecto del toro y ser embestidos. También es común que este tipo de percances provoque pleitos entre los vaqueros, quienes consideran que el accidente ha sido provocado por la imprudencia de otro vaquero, o de plano tengan viejas rencillas y busquen cualquier pretexto para saldarlas.

\section{La sacralización}

En muchas comunidades un grupo de feligreses pasea una imagen del santo patrono dentro del ruedo después de haber toreado dos o tres toros, lo que puede hacerse todos los días en que hay corridas, como es el caso del municipio de Dzitas. En otras comunidades el paseo de la imagen por el ruedo se lleva a cabo el domingo, cuando más gente acude a gustar la corrida. En el paseo los feligreses cargan en andas la imagen patronal, cuando se trata de una imagen de bulto, o bien es solamente una persona la que lleva una pintura o un cuadro con una fotografia, o una litografia. En cualquier caso, siempre se detienen un momento en la entrada al ruedo, en tanto que algunos colaboradores piden a los toreros, prestadas, una o dos capas para recolectar las limosnas que los espectadores arrojan desde los palcos como ofrenda a la imagen. En algunas ocasiones los propios toreros colaboran sujetando el capote mientras se hace 
el recorrido por el ruedo. Por delante y detrás de la imagen va un grupo con la capa extendida. Durante el tiempo que la imagen hace su recorrido la charanga interpreta un himno religioso, que puede ser el de "Cristo rey" o el de "María, madre mía”. En el trayecto los espectadores arrojan dinero en los capotes extendidos. Siempre hay cerca de la imagen personas pendientes del dinero que pueda caer fuera de lugar, para recogerlo y echarlo dentro de las limosnas. Al final del recorrido la imagen es puesta de nueva cuenta en la entrada, frente a todos, la cual es inclinada ligeramente a manera de agradecimiento, mientras levantan los capotes con el dinero. En ese momento se interpretan dianas y los espectadores brindan un fuerte aplauso. Más tarde, en la parroquia, al terminar la misa correspondiente al día, el sacerdote informa sobre el monto de la recaudación hecha en la corrida y el destino que se dará al dinero reunido.

\section{Las charlotadas}

Una de las corridas más interesantes es la que marca el final de la fiesta, es la llamada charlotada o corrida de charlotes. Por lo general dichas corridas se inician el sábado por la tarde y continúan el domingo, para concluir el lunes. En algunos municipios se realizan dos corridas al día, una por la tarde y otra por la noche. Los toreros que se encargan de hacer las faenas se visten de mujeres, principalmente, caracterizando a una "mestiza", a la negra Tomasa, al diablo y a la muerte. La mestiza viste un huipil viejo y maltrecho, lleva un maquillaje excesivo en mejillas, párpados y labios; la negra Tomasa se viste con un atuendo ancho, acentuando con globos glúteos y pechos, en la cabeza se amarra un pañuelo rojo, cruzándolo por la parte de la nuca y abundándolo ligeramente por encima de la frente. El color negro con el que se maquilla cara, brazos y piernas se consigue del hollín acumulado en ollas y comales, el cual se mezcla con un poco de crema dermatológica, o simplemente con un poco de aceite comestible. El diablo se viste con un traje entero de color rojo, con cuernos y cola de tela; la muerte se viste igualmente de traje entero, pero en color negro y con rayas y figuras que dibujan el esqueleto humano.

Cada uno de estos personajes se encarga de jugar con el toro, ya sea con la cola del diablo, con la muerte corriendo y agarrando la cola del toro o con la falda de la negra Tomasa. Durante la corrida acosan al toro entre los cuatro personajes, hasta lograr sujetarlo por los cuernos y la cola, mientras otro se sienta en el cuello y otro más en el lomo; por lo general se trata de toretes o vaquillas. Otro de los aspectos que se puede observar durante la charlotada es la intervención de varones jóvenes, quienes se involucran con los personajes de la charlotada. Por su parte, el juez se limita a observar desde su caballo y da órdenes como en las corridas anteriores. Al concluir el espectáculo de la charlotada se da oficialmente por concluida la fiesta y los palqueros comienzan a desbaratar los tablados y los palcos. 


\section{La trama ritual de las corridas}

Para reconocer el significado de las corridas de toros en la cultura de los pueblos mayas orientales es necesario considerar la compleja trama por la que se articulan al ciclo ritual de las fiestas patronales; mirar a las corridas aisladamente y compararlas con la tradición ibérica en sus diversas manifestaciones contemporáneas, impide asumir las particularidades que ha asumido entre los pueblos mayas, al grado de contener un conjunto de referentes simbólicos que nos remiten a la versión maya de la cosmovisión mesoamericana.

Una forma frecuente por la que se separa a la corrida de toros en los pueblos mayas de su contexto ritual es la que distingue los aspectos profanos de aquellos sagrados, ubicando en la primera categoría a la corrida, junto con la feria, los bailes y los banquetes de los gremios participantes. Sin embargo, es necesario destacar el hecho de que en las fiestas patronales, y en todas las manifestaciones rituales comunitarias, nos encontramos con el enfrentamiento de dos tradiciones religiosas profundamente diferentes, cada una de las cuales establece sus propios parámetros y, en el largo periodo de su confrontación, medio milenio, han configurado sus espacios de síntesis, de alternancia y de franca imposición; pero siempre en una situación dinámica y oscilante.

Por una parte está la tradición cristiana impuesta por los invasores europeos, en la variante medieval de la orden franciscana, que se constituye en la hegemónica y tiene como espacio central la iglesia de la comunidad. Éste es el espacio de los grandes rituales comunitarios, con sus procesiones multitudinarias y su rica parafernalia medieval, de santos en andas, palios, de sahumerios que saturan el aire con el humo de sus resinas, música, cohetes, cantos y rezos. A este ceremonial se incorpora la iglesia contemporánea a través del sacerdote y su actividad pastoral, en una situación que puede confrontarlo con la tradición religiosa comunitaria, la que puede sortear a través de respetar y tratar con tacto a los representantes locales. Cuando no sucede así, se provocan los enfrentamientos y los conflictos entre comunidad y sacerdote, lo que es frecuente por la rígida ortodoxia de la Iglesia católica. Desde esta perspectiva católica lo sagrado se relaciona con la iglesia y con las imágenes que guarda, particularmente el santo patrón de la comunidad; a esto se añaden los altares y las imágenes de los gremios, con todos sus emblemas, como son las banderas, los pabellones y los estandartes. El resto de los eventos comunitarios y familiares cae entonces en el ámbito de lo profano.

Sin embargo, si asumimos la perspectiva de la cosmovisión mesoamericana, los referentes simbólicos son otros y se establecen otras coordenadas, de tal suerte que todos los eventos se insertan en un ciclo ritual que constituye la fiesta patronal, la cual despliega su realización en una matriz espacio-temporal bien delimitada. Contra la tendencia general de asumir la presencia de la tradición religiosa mesoamericana como una supervivencia cultural, o bien contaminada por lo que ambiguamente se ha llamado "modernidad", o peor aún "posmoder- 
nidad", nosotros partimos del hecho de la presencia viva de la concepción del mundo mesoamericano a partir de la continuidad de dos ámbitos: el del trabajo agrícola en torno al maíz, el que, como apunta el historiador Sergio Quezada (2001: 60), los pueblos mayas siempre han mantenido el monopolio, y el de la lengua maya, en la que establecen las categorías de su cosmovisión. A esto añadamos que el trabajo agrícola está inscrito en una concepción ritual por la cual se establecen relaciones de reciprocidad con todo el entorno y se erige una tradición civilizatoria muy antigua y compleja.

Mientras que para la tradición cristiana el trabajo es un castigo divino, para los pueblos mesoamericanos el trabajo es una oportunidad de dialogar e intercambiar dones con las entidades anímicas que constituyen el mundo, concepción que se cristaliza en el papel central del maíz, en la mitología y en la ritualidad. Precisemos que reconocemos una religiosidad comunitaria y regional maya, que tiene como trasfondo y sustento a la cosmovisión mesoamericana. A partir de esta base se establece, desde la condición hegemónica del catolicismo y de las instituciones estatales y nacionales, un diálogo y un intercambio en el que se negocia constantemente la presencia y vigencia de las dos tradiciones culturales.

\section{La cosmovisión: la dimensión espacial}

Vale la pena, en este momento, referirnos, así sea esquemáticamente, a las características de la matriz espacio-temporal de la cosmovisión mesoamericana entre los pueblos mayas. En este sentido son clásicas las contribuciones del antropólogo yucateco Alfonso Villa Rojas, desde su monumental monografia sobre los mayas de Tusik, en Quintana Roo, hasta sus últimos ensayos sobre diversos tópicos relacionados con la cosmovisión (Villa Rojas,1980, 1986, 1987), las cuales se han enriquecido con las investigaciones recientes de varios investigadores, entre los que destaca el equipo coordinado por la antropóloga, también yucateca, Ella Fanny Quintal (2003a y 2003b), y en cuyas contribuciones nos apoyaremos en lo que sigue.

En términos de la cosmovisión de los pueblos mayas, la espacialidad tiene como referentes generales, en un sentido horizontal, los cuatro rumbos y el centro, es decir un quincunce, en el que también se distinguen las esquinas como puntos significativos; en tanto que en sentido vertical están el cenit y el nadir. El punto más importante, el que reúne y sintetiza a los seis restantes, es el centro, al que se representa simbólicamente por el árbol sagrado, el ya'axche', la ceiba. Por otra parte, y ya situándonos en el mundo, se reconocen tres niveles: el cielo, ka'an, la superficie terrestre, yóok'olkab, y el inframundo, yáanal lu'um. "La faz de la tierra y el inframundo se hallan indisolublemente ligados, separados apenas por una tenue frontera; en la parte de arriba se encuentra el espacio de la vida y en la de abajo el de la muerte. Vida y muerte conforman un todo apenas diferenciable. El cielo está arriba de la tierra, es el lugar de los espíritus, creadores 
de la vida" (Quintal, 2003b: 280). Estos tres niveles se vinculan entre sí por una brecha imaginaria que los cruza, a la que se llama kuxa'an suum, "cuerda viviente, cordón umbilical", "camino estelar sagrado, axis mundi, eje del cosmos, representado en las fuentes arqueológicas y en los documentos maya coloniales por la ceiba (ya'axche'), el árbol sagrado de los mayas" (op. cit.: 281).

El paisaje es para los mayas un espacio ocupado por diferentes entidades y marcado por diversos referentes sagrados, en donde cuevas, cenotes, cerros, el monte, tienen su respectivo dueño. "El carácter sagrado de estos lugares deriva de su papel nodal en el esquema cosmogónico maya $|\ldots|$ cuevas, pozos, cavernas, cenotes, son entradas al inframundo, al reino de la muerte, al lugar de residencia de kisin [... la pirámide, el 'cerro', el múul representan en cierta forma a los ancestros, porque son el camino que recorren en su ascensión a los cielos. De esta forma, los caminos son expresión horizontal del axis mundi que une los tres niveles del cosmos, pero también a los ancestros con los seres vivos" (op. cit.: 285). Todos estos sitios son cuidados por sus dueños, los yumtsilo'ob. "Por lo general, estos seres suelen aparecerse en el monte, en la entrada de una cueva, de un cenote, de una milpa, sobre un cerro o sobre los antiguos caminos, pero nunca se aparecen en el pueblo, a menos que en él exista alguno de los lugares antes señalados. Tampoco aparecen en los cementerios, porque es el territorio de los pixano'ob (las ánimas) pero no de los iik'o'ob (los espíritus)" (loc. cit.).

Desde el punto de vista de la actividad humana, del trabajo, se señalan tres ámbitos: el monte, la milpa y el pueblo. El primero, k'áax, es un espacio peligroso, ocupado por los dueños, del que se toma lo necesario para vivir, para lo que es necesario pedirles permiso, "dando algo a cambio, regresando como desagravio parte del alimento que de él se obtiene". Cuando se roza el monte alto se avisa a los "dueños" a través de oraciones y de ofrendas, para que al caer los árboles derribados no dañen al milpero. "También con los animales establece el maya la misma relación que con los árboles; pedir permiso, desagraviar a los dueños, mantener el equilibrio". Por su lado, la milpa, kool, el otro ámbito, es un territorio liminar, no del todo bajo el control de los dueños del monte, ni del hombre. El primer paso para establecerlo es su medición, cuadrándolo con ayuda de estacas y cordeles; se forman mojoneras, donde residirán los cuidadores de la milpa, los kanan xu'uk'es, situados en las cuatro esquinas.

Durante todo el ciclo agrícola se continúa la relación de intercambio recíproco entre el hombre y los señores del monte y de la lluvia, los guardianes y los vientos. Las ofrendas son necesarias para poder entrar y usar este lugar sagrado, para que los "dueños" ahuyenten a sus "animalitos" y dejen a la milpa libre de los peligros del monte y también para que se logre buena cosecha. Este vínculo e intercambio se mantiene a través del maíz, "santa gracia", producto de la milpa, que se lleva a casa para cocerlo y regresarlo como ofrenda en forma de bebida sagrada. Ofreciendo saka' se agradece, se está a salvo, se alimenta a los "dueños", a los cuidadores, a los dadores de la lluvia (Quintal, 2003b: 309). 
Finalmente, el tercer ámbito es el del pueblo, kaaj, territorio humano por excelencia, protegido por el santo patrón, que tiene sus cuatro accesos simbólicos, en cada uno de los cuales se instala una cruz de madera, cuya forma reproduce a la ceiba, "donde los báalam kaaj o guardianes cuidan al pueblo evitando que entren en él animales y malos vientos del monte". El pueblo tiene un centro, marcado por una plaza donde se ubica la iglesia, sede del santo patrón comunitario y de otros santos que le acompañan, a cuyo lado se construye el ruedo para las corridas de toros. En este espacio se encontraba una gran ceiba, indicando el centro simbólico. En la plaza también se localiza el palacio o comisaría municipal, en cuyos corredores se celebran las asambleas y las "vaquerías".

Rasgo nodal en la definición del centro es, en la mayoría de las comunidades yucatecas, el cenote o pozo, ahora a veces oculto pues su función ha sido sustituida por sistemas de aprovisionamiento de agua potable. Pero sabemos que muchas comunidades mayas tienen su origen en la existencia de una fuente natural de agua, una aguada, un cenote, un pozo: un lugar cotidiano y sagrado en ciertos días y horas, una entrada al inframundo, al mundo de kisin, el señor de la muerte (op. cit:: 311).

Este centro de la comunidad es el espacio donde se celebran los grandes rituales, como la fiesta patronal, cuando se transforma incorporando numerosos indicadores de la condición festiva y sagrada del espacio, como es el ruedo taurino, los juegos mecánicos de la feria, los numerosos puestos de comida, golosinas y bebidas diversas, los adornos de papel de colores que se instalan en cuerdas sobre la plaza, así como en la fachada de la iglesia. Las casas mismas donde residen los presidentes de los gremios involucrados muestran en sus arreglos el carácter festivo, entre los que destaca el altar donde se instalará el santo patrón en el momento correspondiente.

\section{La dimensión temporal}

En esta perspectiva el punto de partida es también el trabajo agrícola en torno al maíz, cuyo ciclo anual, señalado por el movimiento aparente del sol, establece las posiciones principales del universo mesoamericano. El recorrido anual se compone de dos partes: aquella en la que las lluvias están presentes, y por lo tanto presenta la mayor actividad en los campos de cultivo, y la de sequía, dedicada a otras actividades, como la cacería del venado, y ahora el trabajo asalariado. La mitad lluviosa está signada no solamente por una intensa actividad en los campos de cultivo, sino también por una constante actividad ritual que marca los momentos más importantes del ciclo de trabajo. "Es común que se ofrezca saka' cinco veces antes de tumbar, cuando se realiza la quema, cuando se siembra, cuando sale el fruto (entonces se lleva además un pollo asado) y cuando termina la cosecha. Algunos llevan dos jicaritas y las colocan en la parte oriente, pero en general las jicaritas son cinco: la más grande se ofrece al centro" (op. cit.: 309). 
Los más espectaculares rituales relacionados con el trabajo agrícola son aquellos realizados por varias familias, e incluso por toda una comunidad, como la petición de lluvias, el llamado ch'a' cháak, y el ofrecimiento de la "comida de la milpa, wajikool, cuando se recoge la cosecha. Hay también otros rituales menores realizados para proteger las milpas, pero los dos más importantes son los que señalan el comienzo del ciclo, el de petición de lluvias, y el que lo cierra, la "comida de la milpa". Es en todos estos rituales que se transmite y se reproduce la concepción del mundo mesoamericano, en su variante maya, así como en todos aquellos espacios del monte señalados como sagrados, a los que se venera de diferentes maneras.

Otro ámbito en el que se reproduce la cosmovisión es el de las relaciones de parentesco, que tienen como su espacio fundamental, además de la milpa, la casa familiar y cuyo ciclo ritual se constituye con las etapas significativas que marcan el paso del nacimiento a la muerte. Éste es también el espacio en el que se establecen las complejas relaciones con el cuerpo humano, tanto en lo que se refiere a la sexualidad como a las nociones básicas de la relación salud-enfermedad, en las que se manifiesta el dualismo en sus múltiples formas.

Por encima de los rituales agrícolas y de parentesco encontramos los grandes ceremoniales comunitarios que constituyen el ciclo anual, y de los cuales el más importante es el del santo patrón, cuando se expresa en su máxima intensidad el conjunto de símbolos con los que se define, y reproduce, la identidad comunitaria y sus componentes étnicos. Así, el ciclo ceremonial comunitario tiene su clímax en la fiesta patronal, pero también se compone de otros ceremoniales, sea que el patronal se divida en dos o tres fiestas, o bien que se hayan establecido otros a lo largo de los cinco siglos de dominación colonial, como los de Corpus Christi, la Semana Santa, la Navidad y otros más, promovidos con entusiasmo por la Iglesia para recaudar fondos a partir de los servicios prestados a los feligreses comunitarios.

Cada una de las expresiones del ritual comunitario anual tiene una estructura propia, es decir una secuencia temporal marcada por diferentes fases, pero el modelo que posee la mayor complejidad es el correspondiente a la fiesta patronal. El punto de partida es el descenso de la imagen del santo patrón, desde su nicho central en el altar principal a una base que la pone al alcance de la gente. En Dzitas es el traslado de la imagen de Santa Inés a una pequeña base situada frente al altar, en tanto que en Tekax es la bajada de la imagen de San Diego Alcalá desde la ermita, situada en un cerro cercano, en las inmediaciones de la serranía Púuc, a la iglesia principal, situada en la plaza central. Con esto se marca el principio del tiempo sagrado de la fiesta patronal, y ello se indica con el lanzamiento de cohetes a lo largo de toda la ceremonia y la realización del primer rosario, el que abre el novenario, el cual culmina precisamente en el día más importante, el del santo patrón. 


\section{La dimensión acústica}

Es importante destacar que todo el periodo de la fiesta se genera una dimensión acústica por la que se señalan diferentes fases de los rituales y se coordinan los diferentes grupos que participan en cada una de ellas. Esta dimensión tiene tres componentes; por una parte, las campanas de la iglesia, que llaman a las ceremonias religiosas que tienen lugar en la iglesia, como son las misas, los rosarios y las procesiones, y cuya intensidad y ritmo constituyen diferentes mensajes.

Un segundo componente, de mayor complejidad, es el que corresponde a los juegos pirotécnicos, y en donde encontramos una gran diversidad de recursos técnicos, cada uno de los cuales se inserta de manera específica en la secuencia ritual. Aquí mencionaremos los más usuales, con ánimo de ejemplificar, más que de abarcar el fenómeno en toda su complejidad. El hecho central es el papel de marcadores de tiempo y espacio de los acontecimientos rituales, lo que les otorga una calidad comunicativa al grado de reconocer diferentes tipos de mensajes en su expresión dentro del marco de los ceremoniales comunitarios.

De entre los diversos recursos pirotécnicos desplegados en los rituales comunitarios dedicados al santo patrón el más conocido, y frecuente, es el de los "voladores", es decir los cohetes que, montados sobre una larga vara, suben velozmente y estallan con gran estruendo.

\footnotetext{
En el transcurso de las fiestas patronales se emplean en numerosas ocasiones: cuando se cantan las mañanitas en honor al santo patrono de la localidad; para indicar la entrada y salida de los gremios; para convocar a los socios de los gremios a una reunión; para solicitar colaboración durante los preparativos en la casa del presidente del gremio; cuando se baja o sube al santo patrono; durante el recorrido de la procesión; cuando en la iglesia local comienzan o terminan las misas y los rosarios y cuando inician las corridas de toros, entre otros sucesos acontecidos durante estas celebraciones (Angelotti, 2004: 119).
}

Otro juego pirotécnico de uso frecuente en el contexto festivo es el de las "hiladas", consistente en una larga mecha que lleva numerosos tronadores, a intervalos de diez centímetros, que provocan una cadena sucesiva de estallidos potentes y secos. Es usado en el ruedo taurino, a la salida del primer toro, pero también al terminar el rosario que los gremios dedican al santo patrón, así como cuando los miembros de un gremio salen de la iglesia para dirigirse a la casa del presidente, "quemándose una hilada en cada contraesquina que cruce la agrupación, en el preciso instante que asoma el estandarte del santo patrono o durante la procesión del santo por las calles del poblado" (op. cit.: 124).

Las "cascadas" o "lluvias de fuego" se emplean al final de los oficios religiosos en la iglesia, y poco antes de la quema de los juegos más espectaculares, como son los "cipreses" y otros más. "Una vez que termina de quemarse la cascada, los gremios concluyen su participación en el ámbito religioso y proceden con las celebraciones en otros espacios del pueblo, como por ejemplo en el parque cen- 
tral, donde realizan algún espectáculo pirotécnico, dan comienzo al baile público o se dirigen a la casa del presidente del gremio respectivo" (op. cit.: 125).

Finalmente, otro juego pirotécnico que queremos mencionar, por hacer alusión a la tauromaquia, así como a la cultura relacionada con el ganado vacuno, es el de los "toritos", uuakax k'áak'. El "torito" es una estructura de madera a manera de carapacho, cubierta con cartón y forma el cuerpo de un toro, lo que se precisa poniéndole una cabeza con la cornamenta, o simplemente la pura cornamenta. Sobre el cuerpo del torito se instalan diversos recursos pirotécnicos, entre ellos cohetes que salen disparados con una trayectoria en espiral; la estructura es sostenida por una persona, generalmente un joven hábil para correr y azuzar a los muchachos que le torean.

Así pues, el estallido de los diferentes juegos pirotécnicos, en el marco de los rituales comunitarios, transmite diversos mensajes, los cuales son difíciles de descifrar si no se posee la clave de la estructura espacial y temporal de las secuencias rituales:

[...] un volador que truena a las tres de la tarde en dirección norte del pueblo puede indicar el comienzo de la reunión de un gremio determinado; otro volador que truene al mismo tiempo pero en dirección sur puede significar exactamente lo contrario, es decir, la finalización de las actividades de otro gremio o que está por comenzar la corrida, que se convoca a la conjunta o simplemente se contesta el mensaje emitido (Angelotti, 2004: 158).

El tercer componente de la dimensión acústica de los ceremoniales comunitarios alcanza la mayor complejidad técnica y ofrece contenidos de mayor densidad histórica y cultural, nos referimos a la música, y a los conjuntos musicales, que acompaña a los diferentes capítulos de la secuencia ritual. Presente en todos los grandes eventos de la fiesta patronal, matiza cada uno de ellos a través del tipo de melodías que interpreta. Para referirnos someramente a su participación nos remitiremos a los tres espacios más importantes: a) la iglesia y sus relaciones con las actividades rituales de los gremios; b) la plaza central y los corredores de la presidencia o comisaría; y c) la plaza de toros.

Los actos que tienen lugar en la iglesia tienen como su mayor protagonista al santo patrón; a quien se llevan las diferentes ofrendas de comida, los símbolos del gremio (banderas, pabellones, estandartes y ramilletes) y, por supuesto la música. En el camino a la iglesia, la procesión que va de la casa del presidente del gremio es acompañada por la charanga. "Las marchas acompañan las entradas y salidas de los gremios, pero cuando el contingente de estos se acerca a unos cien metros aproximadamente de la iglesia (al llegar a la plaza) la banda cambia de marcha a himno religioso (por lo general iViva Cristo Rey!). Cuando la banda toca a las puertas del templo después de la misa interpreta por lo general marchas" (Quintal, 1993: 13). El tipo de música interpretada, pensamos, marca los diferentes escenarios y las etapas del ritual correspondiente, pero toda la música constituye una expresión religiosa, una ofrenda y una vía de comunicación con el santo. 
La mejor demostración de las implicaciones sagradas que tienen las expresiones musicales y dancísticas es la vaquería misma, con la que se abre el ciclo de grandes rituales comunitarios y tiene como escenarios los corredores del palacio o la plaza central misma. Como apuntamos antes, la vaquería tiene un carácter marcadamente formal, tanto en los requerimientos del atuendo como en los diferentes referentes simbólicos que indican su desarrollo: el inicio con una pieza específica, "Los aires", luego la alternancia en el rito de las jaranas interpretadas, y finalmente la jarana que marca el final, "El toro grande". Bailar la jarana es una forma de ofrenda, "para muchos hombres y mujeres de las comunidades bailar "el toro' o inclusive cualquier jarana de la fiesta es una promesa al santo", e incluso el bailar la última jarana "implica tantos riesgos como su contraparte real, esto es, lidiar un toro" (op. cit.: 14, 23).

En este punto es necesario insistir en los dos diferentes tipos de religiosidad que se ponen en juego en las fiestas patronales, pues desde la perspectiva estrictamente católica el ámbito sagrado se sitúa en la iglesia y en los altares de los gremios; en cambio, en la dimensión otorgada por la cosmovisión mesoamericana incluye todos los eventos enmarcados en el conjunto ritual de la fiesta patronal, y el escenario trasciende a la iglesia y sus alrededores para abarcar toda la comunidad. Esta diferencia se advierte en las concepciones sobre las imágenes, pues mientras para los católicos los santos son objetos sagrados, para las concepciones mesoamericanas, y específicamente para las mayas de que tratamos aquí, son personas. "Para el maya la imagen es el santo mismo y tiene carácter medio humano como los demás dioses mayas. Se cree que puede comer, beber, escuchar música, volverse vengativo o contento. Y en la fiesta se le saca de su lugar en la iglesia para que pueda ver y escuchar los festejos" (Jardow-Pedersen, 1999: 38). En Dzan las puertas de la iglesia se abren cuando comienza la corrida, para que el santo patrón reciba los diferentes mensajes que se emiten desde el ruedo.

La música subraya indudablemente el carácter sagrado de la corrida de toros y nos transmite la complejidad de los acontecimientos que se desarrollan. La charanga se sitúa en los palcos donde se instalan también las autoridades, las embajadoras y los invitados especiales. Antes de subir, acompaña a las autoridades, incluyendo al juez de plaza, a un recorrido por el ruedo, en el sentido opuesto a las manecillas del reloj; es una primera "coronación"; luego todos suben a sus lugares correspondientes. La charanga toca diversas piezas musicales, hasta el momento en el que comienza el paseílo de los toreros, cuando toca un pasodoble.

La charanga, llamada también orquesta jaranera, está compuesta "por un grupo de aliento con dos saxofones altos, un saxofón tenor, dos trompetas y un trombón y el grupo de ritmo que consta de un tambor grande llamado 'bombo', dos timbales y, a veces, un guiiro. Cuando tocan procesiones y corridas de toros el timbalista usa, por razones prácticas, un tambor pequeño o "charola", que es más fácil de transportar y ocupa menos espacio" (op. cit.: 82). Para indicar las fa- 
ses de que se compone una corrida la charanga emplea diez diferentes toques de clarín, desde que se anuncia la salida del toro hasta que se indica que lo saquen, o bien lo maten, pasando por los cambios de tercios y otras órdenes. Cuando el toro que está en el ruedo muestra bravura, la charanga toca una pieza llamada "El torito", un son pequeño de 24 compases. "En algunos pueblos lo tocan cada vez que entra un toro al ruedo" (op. cit.: 107).

Una segunda coronación del ruedo, y énfasis en su condición sagrada, se realiza cuando se suspende la corrida, para dar cabida al recorrido de la imagen religiosa por el ruedo para recoger las aportaciones del público asistente. La charanga toca entonces algún himno religioso y se lanzan varios "voladores", hasta que completa su recorrido, se retira y se reanuda el juego con los toros.

\section{El axis mundi}

Sin embargo, la mayor fuerza en su significación sagrada procede de otras características relativas al diseño del ruedo y, sobre todo, a las implicaciones simbólicas de la corrida misma. El rasgo más evidente, que llama la atención de inmediato, es la presencia de la ceiba sembrada en el centro del ruedo, la cual es un axis mundi que representa a Wan t'ul, el protector del ganado "contra los ataques de los vientos malignos", y está en contacto con la xtabay, habitante del inframundo. "Dicen que la Xtabai se guarda en la espalda del yaxché. Aparece en la noche. Se ve como una mujer desnuda con cabello largo....Porque la Xtabai tiene tres dedos, nada más. Tres dedos, más el grande..." (Jardow-Pedersen, 1999: 37). El ruedo es por lo tanto una representación del universo, cuyas esquinas y cuatro rumbos marca el sacerdote maya local, el jmeen, en sus rituales de protección, en algunas comunidades mayas, como Xalau, estudiada por el etnomusicólogo Max Jardow-Pedersen. En esta comunidad, al sembrar la ceiba, el jmeen vierte una medicina de toro en el hoyo abierto. Al terminar la siembra y pronunciar más oraciones, "un vaquero sube al árbol y derrama una botella con vino ceremonial balché mojando el tronco. El vino es la primera ofrenda a Wan Thul. Más tarde, en la noche, los vaqueros cuelgan piñas, calabazas y cubetas con plantas de chile en las ramas de la ceiba. Todos son regalos que tienen el objeto de satisfacer al dios del ganado y conseguir su protección" (op. cit.: 122).

\section{A manera de reflexión final}

En un primer acercamiento la corrida de toros en los pueblos mayas orientales es un juego en el que participan toreros y vaqueros, como parte de la tradición ganadera de raíz ibérica. Un elemento que emparenta esta tradición peninsular con algunas de las variantes estudiadas por F. Saumade es el hecho de no matar a los toros; incluso tales bestias se convierten en protagonistas de los juegos, 
pues a partir de la experiencia que van adquiriendo en cada corrida aprenden a enfrentar exitosamente a sus rivales. En el caso de las corridas mayas hemos mencionado el que embistan de frente a los vaqueros que tratan de lazarlos para sacarlos del ruedo, con resultados frecuentemente sangrientos al herir a los caballos y a sus jinetes. Entre más bravos son y más bajas causan, van adquiriendo fama, y cuando se anuncian, ya sea el toro mismo o la ganadería a la que pertenece, se crea una gran expectación entre los asistentes por los peligros que presenta, lo que pone a prueba la habilidad de los vaqueros; no necesariamente la de los toreros, que permanecen en un segundo plano.

Sin embargo, el elemento particular de esta tradición maya es el sacrificio de uno de los toros, que con frecuencia es el primero que se lidia; el cual, en varias comunidades, es atado a la ceiba desde la noche anterior. En el cuerpo suelen pintarse el nombre del donador, o el del santo patrón. Estos toros constituyen ofrendas de algunos ganaderos con el fin de proteger su hato de las enfermedades; ellos lo ofrecen al presidente del gremio, quien lo canaliza a los organizadores de las corridas. Hay todavía una significación de mayor profundidad, implicada en las cuestiones que hemos mencionado:

Aparte de ser un sacrificio al santo patrón, la corrida significa, además, un combate contra los demonios. El toro está siempre rodeado por espíritus malignos que le siguen al ruedo. Así, el animal adquiere características medio sobrenaturales y la corrida constituye, más bien, una lucha contra los demonios más que contra el toro mismo. Los vientos malignos del ruedo podemos describirlos como una imagen del desequilibrio del universo, donde los poderes positivos tratan de vencer a los negativos, o al revés. Sin embargo, al entregar las ofrendas necesarias — como la corrida-, o sea, el combate contra los vientos malos, se restablece el equilibrio del universo (Jardow-Pedersen, 1999: 127).

El carácter sacrificial de la corrida de toros es subrayado por otros rituales que, si bien no son públicos, se realizan en la intimidad de las casas de los presidentes de los gremios. Tal es el caso, ya aludido antes, del sacrificio de guajolotes y de cochinos en el marco de las comidas rituales de los gremios. Los guajolotes, o como se les llama en los pueblos peninsulares, pavos, son degollados y su sangre se deja escurrir en la tierra, en el huerto de la casa; el número de pavos sacrificados es un rasgo que indica la importancia y el prestigio del gremio responsable, y de su presidente. Lo cierto es que el número de pavos sacrificados es considerable, pues son por lo menos treinta animales, grandes en su mayoría. Cada día un gremio diferente repite el mismo ritual de sacrificio a lo largo de la fiesta. Y lo mismo sucede con los cerdos, cuya cabeza, ya cocida, es usada en una danza por la cual se expresa la transmisión del cargo, pues el gremio saliente la entrega al que tomará su lugar para el año siguiente. El ritual se realiza en la plaza central y en la iglesia, donde se acompaña de "ramilletes", unas elaboradas estructuras hechas con varas y recubiertas con papel de colores, el que es recortado y combinado con un espléndido sentido artístico. 
Pavos y cerdos se preparan en la casa del presidente del gremio para ser cocinados en un horno subterráneo, el pib, o bien en el fogón tradicional. El pavo se prepara con una salsa de chiles tostados y molidos, los cuales le dan una coloración negra al guiso, el llamado "relleno negro", el platillo ritual por excelencia. El que tanto los pavos como los cerdos sacrificados sean enterrados para su cocción remite a las concepciones sobre el inframundo, acentuadas por la preeminencia del color negro; esto, sin embargo, es una cuestión que merece mayores investigaciones, pero que, por otro lado, se articula con la interpretación sobre su carácter sacrificial, como parte de las ofrendas que se hacen en las fiestas patronales.

Nuestra intención en este ensayo, finalmente, ha sido realizar una primera aproximación a las corridas de toros entre las comunidades mayas peninsulares para mostrar, así haya sido esquemáticamente, la complejidad de una tradición que, habiendo llegado de Europa, ha sido reelaborada y reinterpretada desde la perspectiva de la visión del mundo mesoamericano, en su versión maya. Esta complejidad se trasluce en la densa trama de los rituales que constituyen las fiestas patronales, pero sin duda se requieren diferentes investigaciones para profundizar en esa complejidad y conocer esta parte de las tradiciones de los pueblos mayas. Hay en todo esto un reto teórico, pues este tipo de expresiones culturales, las relacionadas con el manejo del ganado traído por los invasores europeos, han sido poco exploradas por la etnografía mexicana, $y$ buena parte de ellas se aferran a los enfoques de una etnografía mesoamericanista atada las viejas concepciones que analizan los fenómenos religiosos desde perspectivas eurocéntricas, con las categorías de las grandes tradiciones religiosas, en las que la noción de sincretismo tiene un papel central.

Las concepciones de una vieja etnografía que arrastran todavía diversas nociones de las teorías de la "aculturación" han insistido por mucho tiempo en distinguir los elementos europeos de aquellos otros mesoamericanos, a los que se arqueologiza con el término de "prehispánicos", todo lo cual conduce a nociones de raíz evolucionista como las de "supervivencia". Esta perspectiva teórica ha acentuado el papel activo de la cultura dominante, lo que llama G. M. Foster la "cultura de conquista", frente a un carácter pasivo, receptor, de las culturas dominadas, colonizadas. Todo lo cual conduce a concepciones distorsionadas, unilaterales, que pierden de vista el carácter dinámico y creativo de las comunidades campesinas de raíz mesoamericana.

Como la descripción de las corridas de toros nos muestra, las comunidades reciben le densa impronta de la tradición ecuestre y de tauromaquia a través de las haciendas ganaderas y de las celebraciones españolas que tienen lugar en las grandes ciudades: sin embargo, estas instituciones y sus tradiciones son apropiadas y reelaboradas desde la perspectiva de la tradición cultural de raíz mesoamericana. La apropiación es dinámica, asumiendo diversas variantes y formas de acuerdo con las presiones de un entorno que puede ser hostil, o tolerante, o incluso indiferente. Cuando es hostil y agresivo, las comunidades negocian; en 
cambio en situaciones de tolerancia o indiferencia se generan diversos procesos de reconstitución cultural con formas variadas de reelaboración. La "guerra de castas" impone un doloroso y brutal trauma histórico en los pueblos peninsulares, pero los más golpeadas son las comunidades mayas; y esto se expresa en numerosas y diferentes facetas de su cultura y de su historia, particularmente en los rituales comunitarios. Si bien la política agraria y el nacionalismo ofrecen un relativo respiro a las comunidades campesinas mayas, no así a las afectadas por la economía henequenera, no es sino hasta ahora, con el auge de los grandes centros turísticos en los que se da trabajo a numerosos campesinos, cuando se propicia, con los recursos volcados sobre las comunidades, una nueva fase de reconstitución, y las corridas de toros de tradición maya pueden ser un buen ejemplo de estos nuevos procesos.

\section{Bibliografia}

Angelotti Pasteur, Gabriel

2004 Artesanía prohibida. De cómo lo tradicional se convierte en clandestino. México, INAH/ El Colegio de Michoacán/ Universidad Autónoma de Yucatán.

Bracamonte y Sosa, Pedro

2005 "Los solares urbanos de Mérida y la propiedad territorial indígena en el Yucatán Colonial", pp. 129-142. En: Yanes, Pablo, Virginia Molina y Óscar González, coordinadores, Urbi indiano. La larga marcha a la ciudad diversa. México, Dirección General de Equidad y Desarrollo Social, Gobierno del Distrito Federal/ Universidad Autónoma de la Ciudad de México, 2005.

Foster, George M.

1962 Cultura y conquista: la herencia española de América. Xalapa, Universidad Veracruzana.

Jardow-Pedersen, Max

1999 La música divina de la selva yucateca. México, Dirección General de Culturas Populares, CONACULTA.

Martínez Saldaña, Tomás

1997 La Diáspora Tlaxcalteca. Colonización agrícola del Norte mexicano. México, Gobierno de Tlaxcala, 1997.

Morayta Mendoza. L. Miguel

1992 Los toros. Una tradición de gusto y reciprocidad de los campesinos morelenses. México, INAH.

Quezada, Sergio

2001 Breve historia de Yucatán. México, El Colegio de México/ Fondo de Cultura Económica, 2001.

MEDINA Y RIVAS / LAS CORRIDAS DE TOROS EN LOS PUEbLOS MAYAS ORIENTALES 
Quintal Avilés, Ella Fanny

1993 Fiestas y gremios en el oriente de Yucatán. Mérida, Gobierno de Estado de Yucatán/ CONACULTN/ INAH/ Patronato de las Unidades de Servicios culturales y Turísticos del Estado de Yucatán, 1993.

Quintal Avilés et al.

2003a "Solares, rumbos y pueblos: organización social de los mayas peninsulares", en Millán, Saúl y Julieta Valle, coordinadores, La comunidad sin límites. Estructura social y organización comunitaria en las regiones indígenas de México, Vol. 1: 291-382. México, ıNAH, 2003a.

2003b "U lu'umil maaya wíniko'ob: la tierra de los mayas", en Barabas, Alicia M.+ coodinadora, Diálogos con el territorio. Simbolizaciones sobre el espacio en las culturas indigenas de México, Vol. I: 273-359. México, INAH, 2003b.

Saumade, Frédéric

2006 Las tauromaquias europeas. La forma y la historia, un enfoque antropológico, Sevilla, Fundación Real maestranza de Caballería de Sevilla/ Universidad de Sevilla/ Universidad de Granada/ Fundación de Estudios Taurinos.

Viqueira Albán, Juan Pedro

2001 ¿Relajados o reprimidos? Diversiones públicas y vida social en la ciudad de México durante el Siglo de las Luces. México, Fondo de Cultura Económica.

Villa Rojas, Alfonso

1980 "La imagen del cuerpo humano según los mayas", Anales de Antropología, Vol. XVII, tomo II: 31-46. México, unam.

1986 "Los conceptos de espacio y tiempo entre los grupos mayances contemporáneos", en: León Portilla, M., Tiempo y realidad en el pensamiento maya. México, unam.

1987 Los elegidos de Dios. Etnografía de los mayas de Quintana Roo. México, Instituto Nacional Indigenista.

Weckmann, Luis

1996 La herencia medieval de México. México, El Colegio de México/ Fondo de Cultura Económica. 